\title{
Measuring fugitive emission in the printing sector as a verification of the solvent management plan according to the EU Solvent Directive
}

\author{
J. Van Deun ${ }^{1}$, R. De Fré ${ }^{1}$, I. Bilsen ${ }^{1}$, R. Baert ${ }^{2} \&$ M. Blondeel ${ }^{2}$ \\ ${ }^{I}$ Department of Environmental Measurements, \\ Flemish Institute for Technological Research (VITO), Belgium \\ ${ }^{2}$ Environmental Inspectorate Division of the Flemish Government, \\ Belgium
}

\begin{abstract}
In order to reduce emissions of volatile organic compounds the EU Solvent Directive 99/13/EC sets fugitive emission limits as a percentage of annual solvent input. A solvent management plan is given in annex III, to calculate the fugitive emission value from paper data of solvent inputs and outputs, and to demonstrate compliance. In a project for the Environmental Inspectorate Division of the Flemish Government we measured fugitive emissions at three different sites in the printing sector, all equipped with regenerative incinerators. Several experimental measurement techniques were applied, with the aim of demonstrating the feasibility of checking the reported solvent emissions independently. It was found that in all three cases the fugitive emissions are considerably higher than those reported in the solvent mass balances according to the Directive. The main reasons for the great underestimation are the unfounded assumption of $100 \%$ effectiveness of vapour capture by ventilation systems, and the wrong allocation of emission flows to the output terms $\mathrm{O} 1$ and $\mathrm{O} 4$, which in one case led to a 10 -fold lower fugitive emission estimate. We conclude that verification of solvent balance by measurements is necessary to underpin emission reports and national emission data. Our results show that there is a risk that the Solvent Directive is not an effective policy instrument without the proper measurements for verification.

Keywords: Solvent Directive 99/13/EC, solvent management plan, solvent balance, printing, VOC measurement, fugitive emission value, $\mathrm{Ol}$ and $\mathrm{O} 4$, incinerator.
\end{abstract}




\section{Introduction}

In many industrial processes volatile organic compounds (VOCs) are used, e.g. in the printing and coating sector. This concerns mostly large-scale processes in sectors were the traditional modes of operations cause fugitive VOC emissions. These VOCs in combination with nitrogen oxides $\left(\mathrm{NO}_{\mathrm{x}}\right)$ largely contribute to the formation of photochemical smog in the sunlit atmosphere through their photochemical degradation pathways Atkinson [1]. In these pathways the formation of ozone occurs. Another characteristic of photochemical processes induced by $\mathrm{VOC}$ is the enhanced formation of aerosols Bowman et al [2]. In order to prevent or reduce the VOC emissions, the European Community introduced the Solvent Directive in 1999 (EU 99/13/EC [3]).

\section{Solvent Directive}

Annex IIA of the Solvent Directive sets emission limit values in the waste gases $\left(\mathrm{mg} \mathrm{C} / \mathrm{Nm}^{3}\right)$ and fugitive emission limits as a percentage of annual solvent input. The solvent management plan is given in annex III of the Solvent Directive. This plan serves for following purposes:

- the verification of compliance with emission limit values;

- identification of future reduction options;

- enabling of the provision of information on solvent consumption, solvent emissions and compliance with the Directive to the public.

It provides a framework for a mass balance exercise with inputs $(I 1, I 2)$ and outputs (O1 to O9) of organic solvents. A brief description of the input and output terms is given in Table 2. The fugitive emission (FE) is calculated by eqn (2). The fugitive emission value (FEV) can be determined directly by eqn (3) or indirectly by eqn (4):

$$
\begin{gathered}
F E V(\%)=\frac{100 \times F E}{I 1+I 2} \\
F E=I 1-O 1-O 5-O 6-O 7-O 8=O 2+O 3+O 4+O 9 \\
F E V(\%)=\frac{100 \times F E}{I 1+I 2}=\frac{100 \times(O 2+O 3+O 4+O 9)}{I 1+I 2} \\
F E V(\%)=\frac{100 \times F E}{I 1+I 2}=\frac{100 \times(I 1-O 1-O 5-O 6-O 7-O 8)}{I 1+I 2}
\end{gathered}
$$

\section{Measurements at three plants in the printing sector}

In a project for the Environmental Inspectorate Division of the Flemish Government we measured fugitive emissions at three different sites (plants A, B and $\mathrm{C}$ ) in the printing sector, all equipped with regenerative incinerators. Several experimental measurement techniques were applied, with the aim to demonstrate 
the feasibility of checking the reported solvent emissions independently. The reported fugitive emission values are $22 \%$ for plant $\mathrm{A}$ and $3 \%$ for plant $\mathrm{C}$. The inputs of solvents are derived from paper data and the regenerated quantity. The output terms are derived from estimations, emission measurements in ducts and at the outlet of the incinerator and calculations. Plant B has no reported FEV.

The used methods for measuring the VOC emissions are:

- determination of the total ventilation flow of halls by using tracer gas techniques;

- measurements of the solvent concentrations by mobile FID-measurements in workplaces;

- emission measurements in ducts (incl. inlet and outlet of the incinerator) by flow and concentration measurements;

- emission measurements at emission points (doors, windows, ventilation grids, extraction fans, etc) by flow measurements with an anemometer and concentration measurements with a mobile FID and passive samplers.

During the measurement period, the solvent and ink consumption are registered by volumetric and/or mass measurements. Afterwards the solvent balance is filled in for the period of the measurements. The measurement periods are representative for the determination of the FEV.

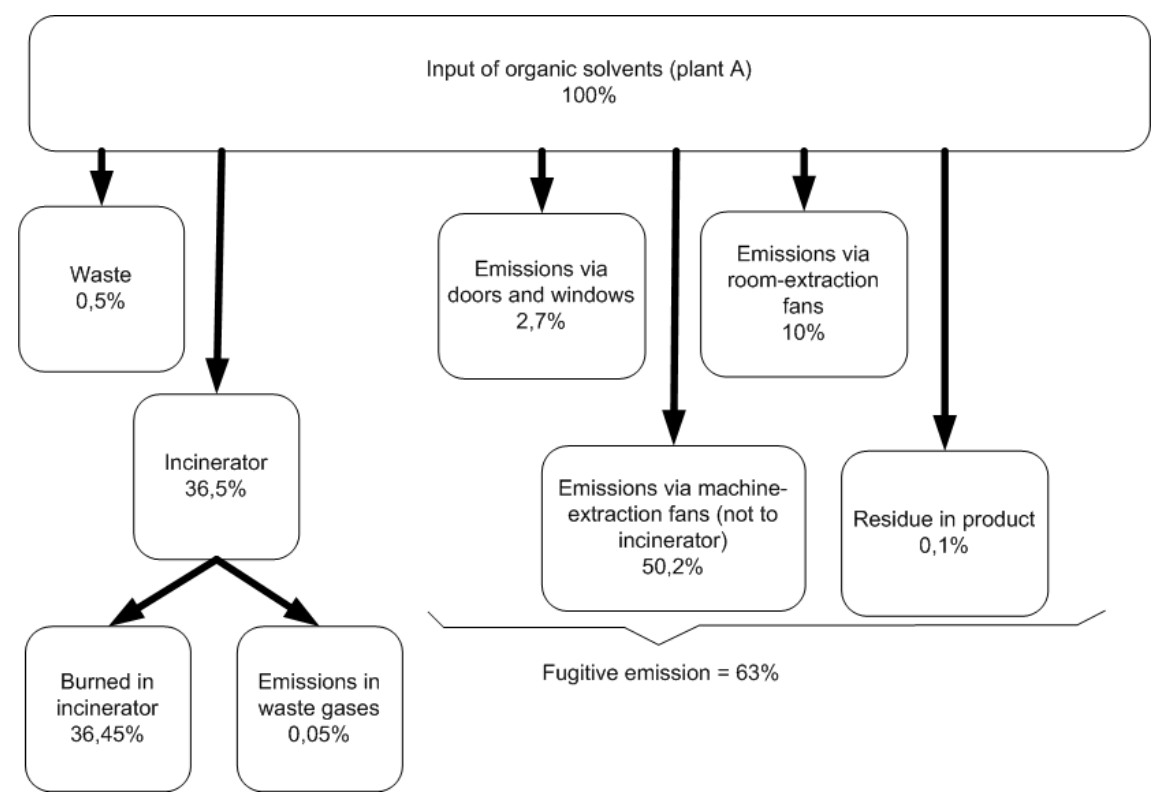

Figure 1: Distribution of the solvents in plant A. 


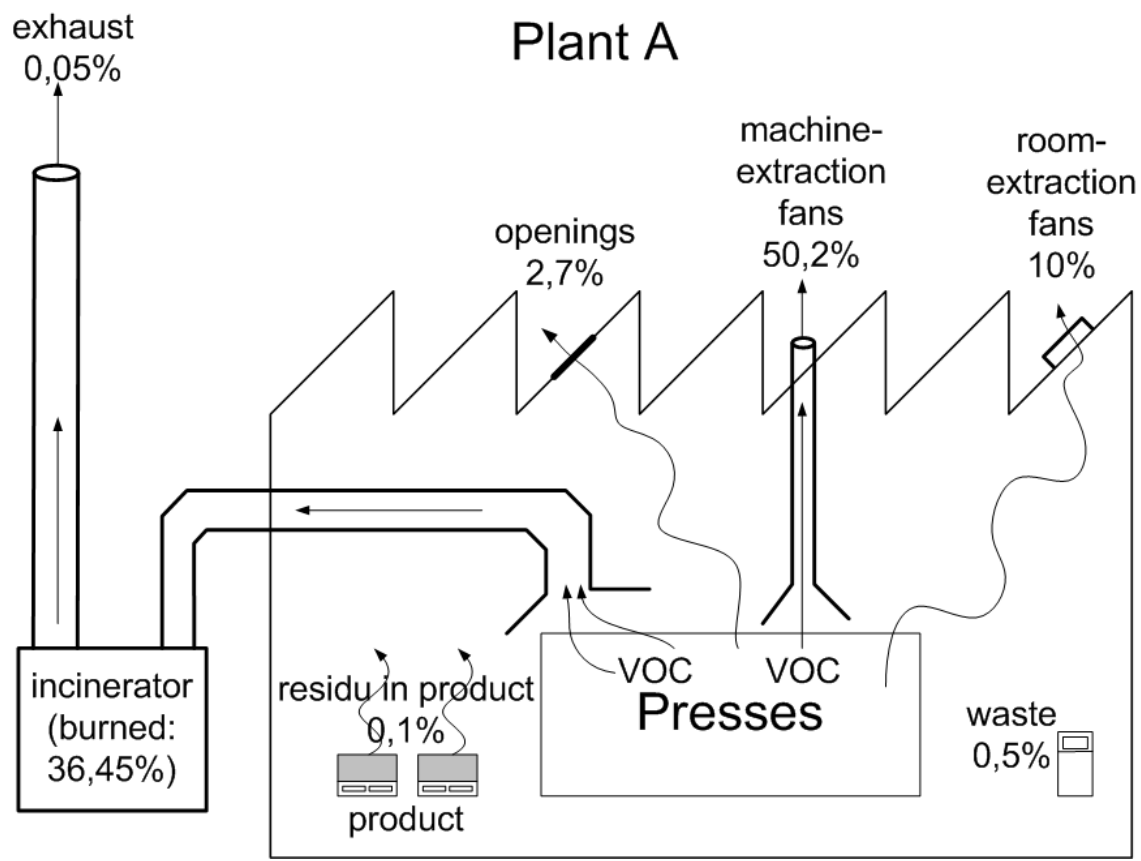

Figure 2: $\quad$ Presentation of the solvent distribution in plant A.

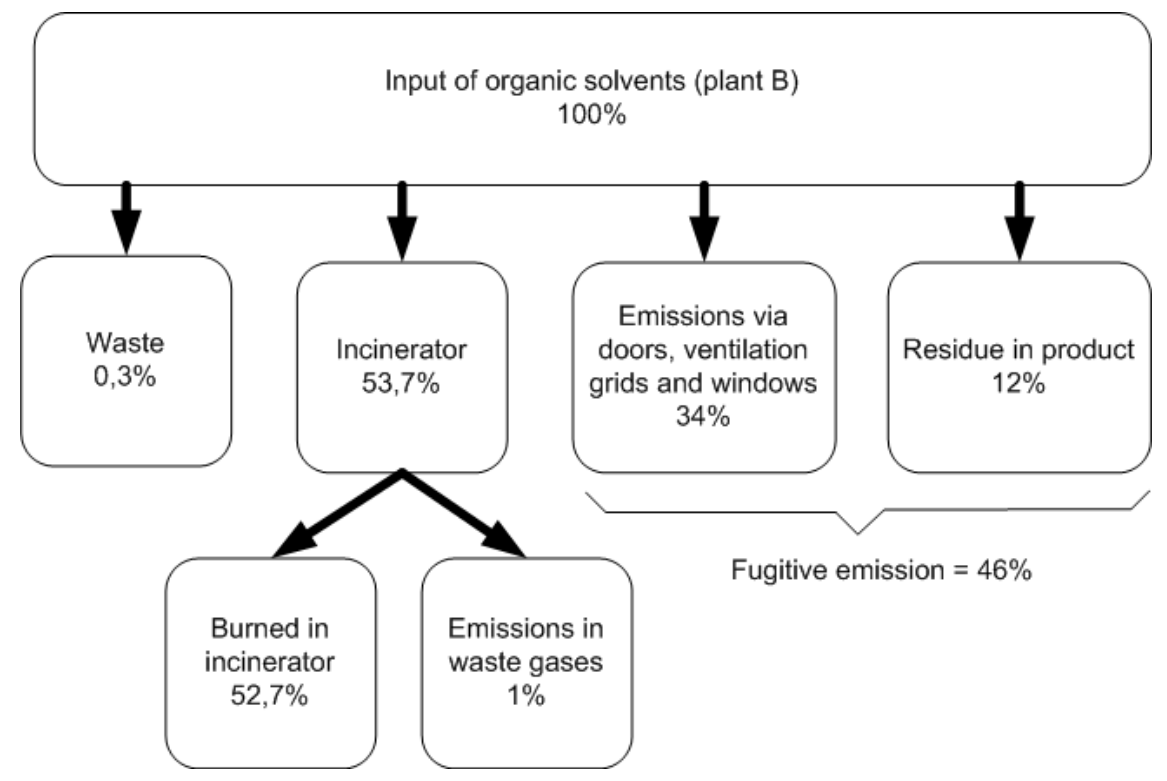

Figure 3: Distribution of the solvents in plant B. 


\section{Results}

\subsection{Distribution of the solvents}

In all the investigated plants, the solvent consumption (C) finally disappears in the waste and the product, are burned in the incinerator and are emitted via openings/extraction fans. For each plant a summary of the solvent distribution based on the results of the used methods is given in Figures 1, 3 and 4 . The VOC emissions of plant A are presented in Figure 2.

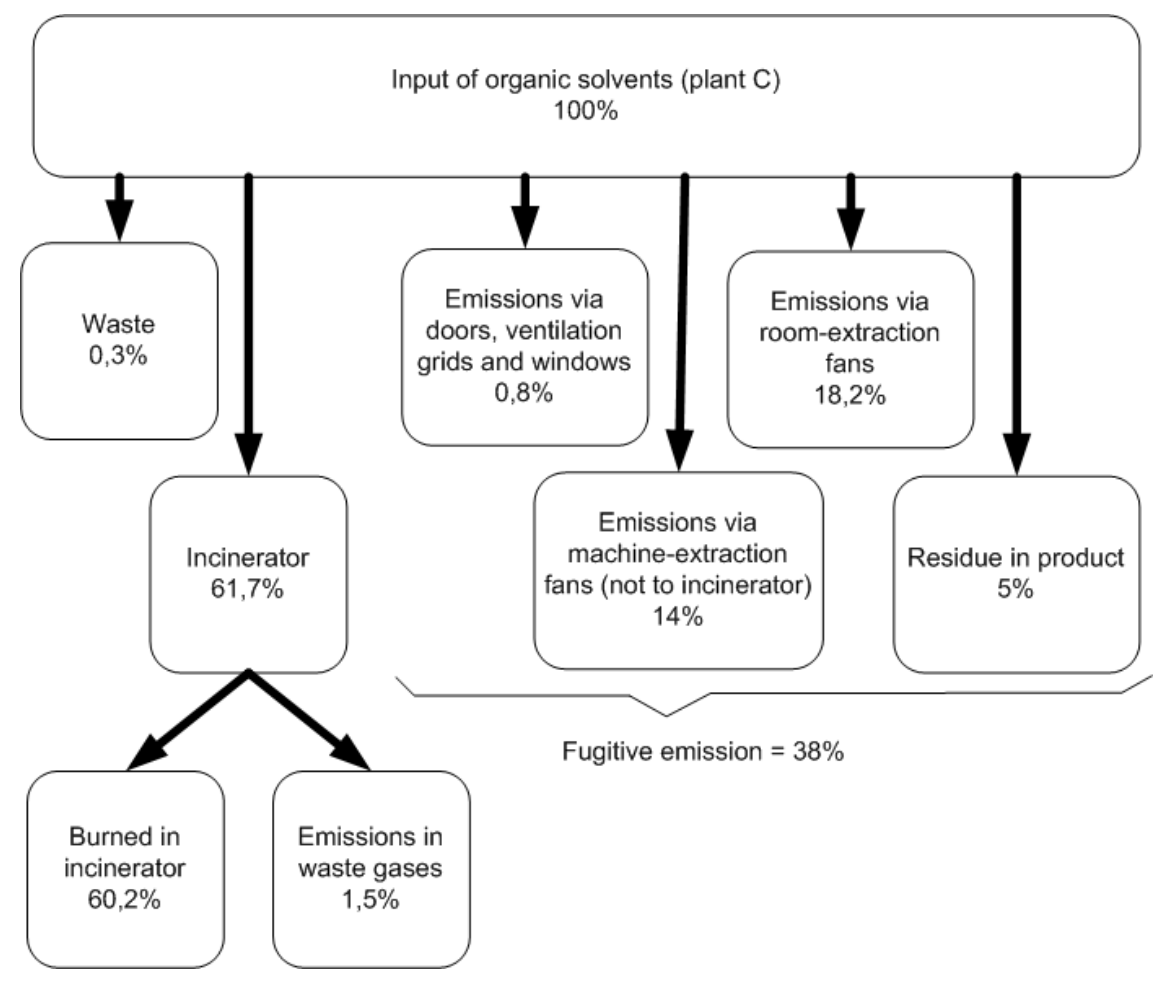

Figure 4: Distribution of the solvents in plant $\mathrm{C}$.

\subsection{Emission values}

The VOC concentrations in the exhaust of the incinerator are measured for 3 hours and the maximum 1 hour average VOC concentration is calculated. The measured emission concentrations in the exhaust of the incinerators did not exceed the limit emission concentration of $100 \mathrm{mg} \mathrm{C} / \mathrm{Nm}^{3}$, Table 1 . 
Table 1: Emission values in the exhaust of the incinerator.

\begin{tabular}{|l|c|c|c|c|}
\hline & $\begin{array}{c}\text { emission } \\
\text { limit value }\end{array}$ & plant A & plant B & plant C \\
\hline max. average enission value of $1 \mathrm{~h}\left[\mathrm{mg} C \mathrm{CNm}^{3}\right]$ & 100 & 10 & 36 & 59 \\
\hline
\end{tabular}

Table 2: $\quad$ Solvent balances based on measurements.

\begin{tabular}{|c|c|c|c|c|c|}
\hline \multicolumn{2}{|c|}{ terms } & \multirow[t]{2}{*}{$\begin{array}{l}\text { emission } \\
\text { limit value }\end{array}$} & \multicolumn{3}{|c|}{ tonnes carbon/year } \\
\hline & & & plant A & plant B & plant C \\
\hline 11 & solvents used as input & & 1000 & 100 & 300 \\
\hline 12 & solvents reused & & 0 & 0 & 0 \\
\hline 01 & emissions in waste gases & & 0,50 & 1 & 4,5 \\
\hline $\mathrm{O} 2$ & solvents lost in water & & 0 & 0 & 0 \\
\hline $\mathrm{O} 3$ & solvent residues in products & & 1 & 12 & 15 \\
\hline 04 & $\begin{array}{l}\text { uncaptured emissions of solvents into } \\
\text { air }\end{array}$ & & 629,0 & 34,0 & 99,0 \\
\hline 05 & $\begin{array}{l}\text { solvents lost due to chemicaliphysical } \\
\text { reactions }\end{array}$ & & 364,5 & 52,7 & 180,6 \\
\hline O6 & solvents in waste & & 5 & 0,3 & 0,9 \\
\hline 07 & $\begin{array}{l}\text { solvents or preparation with solvent } \\
\text { sold }\end{array}$ & & 0 & 0 & 0 \\
\hline 08 & $\begin{array}{l}\text { solvents in preparations recovered for } \\
\text { use }\end{array}$ & & 0 & 0 & 0 \\
\hline 09 & solvents released in other ways & & 0 & 0 & 0 \\
\hline \multicolumn{3}{|c|}{ consumption $=\mathrm{C}=11-\mathrm{O}$} & 1000,0 & 100,0 & 300,0 \\
\hline \multicolumn{3}{|c|}{ fugitive emission $=\mathrm{FE}=11-01-05-06-07-08=02+03+04+09$} & 630,0 & 46,0 & 114,0 \\
\hline \multicolumn{3}{|c|}{ total emission $=\mathrm{FE}+01$} & 630,5 & 47,0 & 118,5 \\
\hline & & & $\%$ & $\%$ & $\%$ \\
\hline \multirow{2}{*}{\multicolumn{3}{|c|}{$\begin{array}{l}\text { fugitive emission value }=\mathrm{FEV}=100^{*} \mathrm{~F} / 1+12 \\
\text { relative expanded measurement uncertainty }(\mathrm{k}=2)\end{array}$}} & 63 & 46 & 38 \\
\hline & & & 17 & 14 & 17 \\
\hline \multicolumn{2}{|c|}{ minimum FEV } & & 52 & 40 & 32 \\
\hline \multicolumn{2}{|c|}{ maximum FEV } & & 74 & 52 & 44 \\
\hline
\end{tabular}

For the calculation of the fugitive emission values and the corresponding expanded measurement uncertainties $(\mathrm{k}=2)$, the solvent balances are made, (see Table 2). The fugitive emissions are measured directly with passive samplers, mobile FID-measurements and the flow measurements with an anemometer (term O4). The emissions in the waste gases (term O1) are measured at the outlet of the incinerator. These results are given in Table 2. For the three plants, there are no solvents lost in water, no solvents or preparations of solvents sold and no solvents in preparations recovered for use. Furthermore, there are no other solvent outputs then the terms $\mathrm{O} 1$ to $\mathrm{O} 6$. So the $\mathrm{O} 2, \mathrm{O} 7, \mathrm{O} 8$ and $\mathrm{O} 9$ terms are not present (terms O2, O7, O8, O9 = 0). The values of the solvent residues in the product (O3) are calculated from the data of the plant (plant A) or from the Dutch guidance document (Verspoor [4]) for plants B and C. The amount of solvents used for washing activities (term O6) are measured. 
The FEV are calculated via eqn (3). The calculated FEV for plant A is $63 \%$, for plant B $46 \%$ and for plant C $38 \%$. The calculated FEVs of the three plants exceed the fugitive emission limit value by a factor 2 to 3 . For each term of the solvent balance the expanded measurement uncertainty $(\mathrm{k}=2)$ is estimated. Finally the measurement uncertainty of the FEV is calculated with GUM-method (ISO guide to the expression of uncertainty in measurement) based on eqn (3). The corresponding (relative) expanded measurement uncertainties for all the calculated fugitive emission values are lower than $20 \%$. Using the expanded measurement uncertainty, the minimum and maximum FEV are calculated, Table 2 .

\subsection{Rooms at negative pressure?}

It was found that in all three cases the fugitive emissions are considerably higher than those reported in the solvent mass balances according to the Directive. The main reasons for the large underestimation are the unfounded assumption of $100 \%$ effectiveness of vapour capture by ventilation systems, and the wrong allocation of emission flows to the output terms $\mathrm{O} 1$ and $\mathrm{O} 4$, which in one case led to a 10-fold lower fugitive emission estimate.

In plant B the VOCs are fugitive emitted via 6 ventilation grids of $2 \mathrm{~m}^{2}$ and 2 openings of $4 \mathrm{~m}^{2}$ (doors). All the captured gases were led to the incinerator. The plant supposed that there are no fugitive emissions because a negative pressure is maintained in the production hall. Emission measurements at the doors and ventilation grids result in a fugitive emission of $34 \%$ of the input via the ventilation grids and the doors. Plant A assumes also that the production halls maintain a negative pressure, but emission measurements results in a fugitive emission of $3 \%$ of the input via the ventilation grids and the doors.

\subsection{Extraction fans}

In plants $\mathrm{A}$ and $\mathrm{C}$, most solvent vapours are captured. A part of the vapours is led to the incinerator (terms $\mathrm{O} 1+\mathrm{O} 5)$ and the other part is emitted via extraction fans in the environment (part of O4-term), see Figure $1.99 \%$ of the emission that is led to the incinerator is burned. The part emitted via extraction fans is first captured by extraction fans and then released. The definitions of the output terms $\mathrm{O} 1$ and $\mathrm{O} 4$ :

- $\mathrm{O} 1$ are emissions of organic solvents in the waste gases.

- O4 are uncaptured emissions of organic solvents to air. This includes the general ventilation of rooms, where air is released to the outside environment via windows, doors, vents and similar openings.

The part emitted via extraction fans is considered as $\mathrm{O} 1$ in plants $\mathrm{A}$ and $\mathrm{C}$, because they consider this as captured emissions. The gases extracted by the extraction fans are totally released in the environment and finally uncaptured. A part of the extractions fans collects gases from the room and the other part collects gases from the presses.

The fugitive emission value is calculated with eqn (3). A decrease of term $\mathrm{O} 4$ in eqn (3), results in a lower FEV. If in plant $\mathrm{C}$ the emissions via the extractor 
fans are considered as $\mathrm{O} 1$, the $\mathrm{FEV}$ is $6 \%$ in contrast to the $38 \%$. So the FEV is dependent on the interpretation of the $\mathrm{O} 1$ and $\mathrm{O} 4$ terms. Legally the emissions in the waste gases have to be measured 2 times a year. At plants $\mathrm{A}$ and $\mathrm{C}$, the emissions are only measured in the exhaust of the incinerator and not at the extraction fans.

If the emissions of the extraction fans are considered as $\mathrm{O} 1$, the VOC concentration limit is $100 \mathrm{mg} \mathrm{C} / \mathrm{Nm}^{3}$, but the measured concentrations are usually 1 to 6 times higher. There is a possibility to dilute the VOC concentrations down to concentrations lower then $100 \mathrm{mg} \mathrm{C} / \mathrm{Nm}^{3}$ by increasing the flow of the fans or the number of extraction fans. But the amount of VOC emitted to the environment is not decreased by these measures. This could not be an objective of the Solvent Directive. There is the need for a guideline for the allocation of the emissions via extraction fans to $\mathrm{O} 1$ or $\mathrm{O} 4$.

\section{Conclusion}

We conclude that verification of solvent balance by measurements is necessary to underpin emission reports and national emission data. Our results show that there is a risk that the Solvent Directive is not an effective policy instrument without the proper measurements for verification. The fugitive emission points are not always known by the plants. Maintaining a hall at negative pressure is not effective in eliminating fugitive emissions.

\section{References}

[1] Atkinson, R., Atmospheric chemistry of VOCs and NOx. Atmospheric Environment, 34, pp. 2063-2101, 2000.

[2] Bowman, F.M., Plinis, C., Seinfeld, J.H., Ozone and aerosol productivity of reactive organics. Atmospheric Environment, 29, pp. 579-589, 1995.

[3] Council Directive 99/13/EC, Official Journal of the European Communities, L85, pp. 1-22, 1999.

[4] Verspoor, P.W., Diffuse oplosmiddelemissies in verpakkingsdiepdruk en flexo. Ministry VROM (the Netherlands), Sitmae Consultancy BV, 2004. 